\title{
Childhood Ovarian Immature Teratoma
}

National Cancer Institute

\section{Source}

National Cancer Institute. Childhood Ovarian Immature Teratoma. NCI Thesaurus. Code C6547.

An immature teratoma that arises from the ovary and occurs in children. 